\title{
Suicide within 12 months of mental health service contact in different age and diagnostic groups
}

\author{
National clinical survey ${ }^{\dagger}$ \\ ISABELLE M. HUNT, NAVNEET KAPUR, JO ROBINSON, JENNY SHAW, \\ SANDR A FLYNN, HAYLEY BAILEY, JANET MEEHAN, HARRIET BICKLEY, \\ REBECCA PARSONS, JAMES BURNS, TIM AMOS and LOUIS APPLEBY
}

\begin{abstract}
Background Suicide prevention is a health service priority but the most effective approaches to prevention may differ between different patient groups.
\end{abstract}

Aims To describe social and clinical characteristics in cases of suicide from different age and diagnostic groups.

Method A national clinical survey of a 4-year (1996-2000) sample of cases of suicide in England and Wales where there had been recent $(<$ I year) contact with mental health services $(n=4859)$.

Results Deaths of young patients were characterised by jumping from a height or in front of a vehicle, schizophrenia, personality disorder, unemployment and substance misuse. In older patients, drowning, depression, living alone, physical illness, recent bereavement and suicide pacts were more common. People with schizophrenia were often in-patients and died by violent means. About a third of people with depressive disorder died within a year of illness onset. Those with substance dependence or personality disorder had high rates of disengagement from services.

\section{Conclusions Prevention measures} likely to benefit young people include targeting schizophrenia, dual diagnosis and loss of service contact; those aimed at depression, isolation and physical ill-health should have more effect on elderly people.

Declaration of interest L.A. is the National Director of Mental Health for England. Funding detailed in Acknowledgements.
Prevention of suicide is a priority for health services in England (Department of Health, 2002). Mental disorder is strongly associated with suicide (Harris \& Barrowclough, 1997; Hiroeh et al, 2001) but the risks and therefore the approaches to prevention may differ between different groups of patients. Two of the most important influences on the risk of suicide are age and psychiatric diagnosis. Physical health problems and major depression are common in suicide in older age-groups (Conwell et al, 1996; Harwood et al, 2000; Timonen et al, 2002) whereas relationship problems and drug misuse are frequently associated with suicide in young people (Appleby et al, 1999; Houston et al, 2001). Although studies have investigated the relationship between suicide and individual psychiatric disorders (e.g. Isometsa et al, 1994, 1996; Rossau \& Mortensen, 1997; Høyer et al, 2004), few studies have collected comparable data on a range of diagnostic groups or explored their clinical care prior to suicide. This paper describes a national consecutive series of suicide by people in contact with mental health services. The aims of the study were to identify the characteristics of patients within the main age and diagnostic groups who died by suicide and to describe aspects of their clinical care prior to death. The study was carried out as part of the National Confidential Inquiry into Suicide and Homicide by People with Mental Illness (Appleby et al, 2001).

\section{METHOD}

Data collection had three stages as described by Meehan et al (2006, this issue). Information on all deaths in England and Wales receiving a verdict of suicide or an open verdict at coroner's inquest was obtained from the Office for National Statistics. The cases presented here consist

†See pp. 129-134 and 143-147, this issue. of deaths by suicide registered from 1 April 1996 until 31 March 2000. We obtained a sample of individuals who had been in contact with mental health services in the 12 months before death and we collected clinical data about these people by sending a questionnaire to the responsible consultant psychiatrist. The questionnaire consisted of sections covering social/demographic characteristics, clinical history, details of suicide and aspects of care. Clinicians were asked for an ICD-10 primary diagnosis (World Health Organization, 1992) and any ICD-10 secondary diagnoses. One question asked whether the death occurred as part of a suicide pact.

\section{Statistical analysis}

For the age-group comparisons we divided the cases into the following groups: under $25,25-34,35-44,45-54,55-64,65-74$ and over 75 years, and described social and clinical characteristics. For diagnostic groups we considered patients with the most common psychiatric diagnoses: schizophrenia and other delusional disorders; depressive disorder; bipolar disorder; personality disorder; alcohol dependence; and drug dependence.

This was a descriptive study and the main findings are presented in the tables as proportions with $95 \%$ confidence intervals (CIs). For selected subgroup comparisons not presented in the tables (e.g. for clinical care variables, life events, those who did and did not die in suicide pacts) we used $\chi^{2}$-tests with statistical significance set at $P<0.05$. If an item of information was not known for a case, the case was removed from the analysis of that item; the denominator in all estimates is therefore the number of valid cases for each item.

\section{RESULTS}

Completed questionnaires were received on 4859 cases, a response rate of $95 \%$. The findings below refer to these cases.

\section{Age-groups}

Rates of contact with mental health services varied according to age-groups as follows: $21 \%$ of those under $25 ; 25 \%$ of the 25 to 34 -year-olds; $27 \%$ of the 35 - to $44-$ year-olds; $26 \%$ of the 45 - to 54 -year-olds; $23 \%$ of the 55 - to 64 -year-olds; $22 \%$ of the 65 - to 74 -year-olds; and $11 \%$ of those over $75\left(\chi^{2}=201.8, P<0.001\right)$. 
Table I Cause of death in those who died by suicide within 12 months of contact with mental health services compared by age-group

\begin{tabular}{|c|c|c|c|c|c|c|c|}
\hline \multirow[t]{2}{*}{ Cause of death } & \multicolumn{7}{|c|}{ Age-group, $n(\%, 95 \% \mathrm{Cl})$} \\
\hline & $\begin{array}{c}\text { Under } 25 \text { years } \\
\quad(n=465)\end{array}$ & $\begin{array}{c}25-34 \text { years } \\
(n=1202)\end{array}$ & $\begin{array}{c}35-44 \text { years } \\
(n=1118)\end{array}$ & $\begin{array}{c}45-54 \text { years } \\
(n=937)\end{array}$ & $\begin{array}{c}55-64 \text { years } \\
(n=540)\end{array}$ & $\begin{array}{c}\text { 65-74 years } \\
(n=380)\end{array}$ & $\begin{array}{c}75 \text { years or over } \\
(n=217)\end{array}$ \\
\hline Hanging & $174(38,34-43)$ & $426(36,34-39)$ & $348(32,29-35)$ & $283(31,28-34)$ & $195(37,33-4 \mid)$ & $107(29,24-34)$ & $52(25,|9-3|)$ \\
\hline Self-poisoning & $129(28,24-32)$ & $348(30,27-32)$ & $375(34,32-37)$ & $305(34,31-37)$ & $154(29,25-33)$ & $144(39,34-44)$ & $55(26,20-32)$ \\
\hline $\begin{array}{l}\text { Jumping/multiple } \\
\text { injuries }\end{array}$ & $96(21,17-25)$ & $184(16,14-18)$ & $134(12,10-14)$ & $96(11,9-13)$ & $64(12,9-15)$ & $28(8,5-10)$ & $19(9,5-13)$ \\
\hline Drowning & $14(3,1-5)$ & $38(3,2-4)$ & $57(5,4-7)$ & $66(7,6-9)$ & $51(10,7-12)$ & $40(11,8-14)$ & $32(15,10-20)$ \\
\hline Burning & $2(0.4,0-1)$ & $22(2,1-3)$ & $26(2,1-3)$ & $16(2,1-3)$ & $5(1,0-2)$ & $8(2,1-4)$ & $2(1,0-2)$ \\
\hline Other' & $23(5,3-7)$ & $55(5,3-6)$ & $49(4,3-6)$ & $71(8,6-10)$ & $34(6,4-9)$ & $27(7,5-10)$ & $37(18,13-23)$ \\
\hline
\end{tabular}

I. Includes cutting, electrocution, firearms, suffocation and other specified.

\section{Method of suicide}

Hanging and jumping from a height or in front of a moving vehicle were most common in those under 25 and least common in those of 65 and over, whereas the frequency of drowning increased with age (Table 1 ).

\section{Social and clinical characteristics}

The male:female ratio was highest in the 25- to 34-year age-group; the proportions of males and females were equal in those over 65. The rate of unemployment decreased with increasing age; nearly twothirds of those under 25 were unemployed. The proportion living alone was highest in the oldest groups; more than half of those over 75 were living alone (Table 2).

The proportion with a diagnosis of schizophrenia or personality disorder decreased with increasing age; half of those under 25 were in these diagnostic groups. The proportion with a diagnosis of depression increased with increasing age; almost two-thirds of those over 65 had depression.

Rates of previous self-harm, violence, alcohol misuse and drug misuse generally decreased with increasing age. Of those under 25 , nearly three-quarters had a history of self-harm and nearly two-thirds a history of drug misuse. In half of those over 75 , the suicide was the first known episode of self-harm. Alcohol and drug misuse were uncommon antecedents in deaths by suicide in those over 65 .

\section{Clinical care}

In-patient suicide was proportionately less common in those aged over 75 (Table 3). The younger groups were more likely to have missed their final appointment with services compared with older patients. Individuals in the under 25 age-group were more likely to be detained under the Mental Health Act 1983 compared with those aged 25 and over (48 v. 25\%, $\left.\chi^{2}=19.6, P<0.001\right)$ and were more likely to be under high levels of observation (33 v. 24\%, $\chi^{2}=2.4, P=0.012$ ). They were also more likely to have discharged themselves (15 v. 10\%, $\left.\chi^{2}=6.2, P=0.012\right)$ and to have been readmitted within 3 months of a previous discharge (22 v. 16\%, $\chi^{2}=3.8, P=0.05$ ).

\section{Adverse life events in the 3 months prior to death}

There were highly significant differences $\left(P<0.001, \chi^{2}\right.$-test $)$ between age-groups in the incidence of adverse life events in a number of domains (relationship problems, unspecified legal problems, physical health problems and bereavement). Relationship problems were most frequent in the 35 - to 44 -year-olds (33 v. $24 \%$ in other age-groups, $\left.\chi^{2}=30.7, \quad P<0.001\right)$. Legal problems were most common in those under 25 (9 v. 5\% of older cases, $\chi^{2}=9.7$, $P=0.002)$. Physical health problems (18 v. $\left.5 \%, \chi^{2}=137.7, P<0.001\right)$, deterioration in physical health $\left(23 v .7 \%, \chi^{2}=164.3\right.$, $P<0.001$ ), bereavement or anniversary of bereavement $\quad\left(10 \quad v . \quad 5 \%, \quad \chi^{2}=24.9\right.$, $P<0.001)$ were more common in those over 65 than in other age-groups.

\section{Suicide pacts}

Thirty-two people died in a suicide pact $(1 \%, 95 \%$ CI $0-1)$. Death in a suicide pact was proportionately more common in those aged over 65 compared with those under 65 (2 v. $0.45 \%, \chi^{2}=28.8, P<0.001$ ). Individuals aged over 65 who died in a suicide pact were more likely to be married (64 v. 34\%, $\left.\chi^{2}=5.5, P=0.02\right)$ and less likely to be living alone $\left(14 v .52 \%, \chi^{2}=7.8, P<0.01\right)$ than the remainder of this age-group. Respondents were also more likely to have cited ill health in someone else as a possible adverse life event preceding the suicide (23 v. 6\%, $\left.\chi^{2}=6.3, P=0.04\right)$. The most common method of suicide was carbon monoxide poisoning (42 v. 7\% of those not in a suicide pact, $\left.\chi^{2}=55.4, P<0.001\right)$.

\section{Diagnostic groups}

\section{Primary diagnoses}

In 4696 cases (98\% of valid cases), a psychiatric disorder was recorded. The principal primary diagnoses were depressive disorder $(n=1645,34 \%)$, schizophrenia $(n=960,20 \%)$, personality disorder $(n=505,11 \%)$, alcohol dependence $(n=439,9 \%)$, bipolar disorder $(n=391$, $8 \%)$ and drug dependence $(n=216,5 \%)$. The findings below refer to these cases. The remaining $13 \%$ were diagnosed with anxiety disorder $(n=170,4 \%)$, adjustment disorder $(n=166,3 \%)$, dementia $(n=25$, $0.5 \%)$, eating disorder $(n=19,0.4 \%)$ and 'other' specified disorders $(n=160,3 \%)$. Two per cent were reported as having no mental disorder.

\section{Method of suicide}

Those diagnosed with schizophrenia were least likely to die by self-poisoning and 


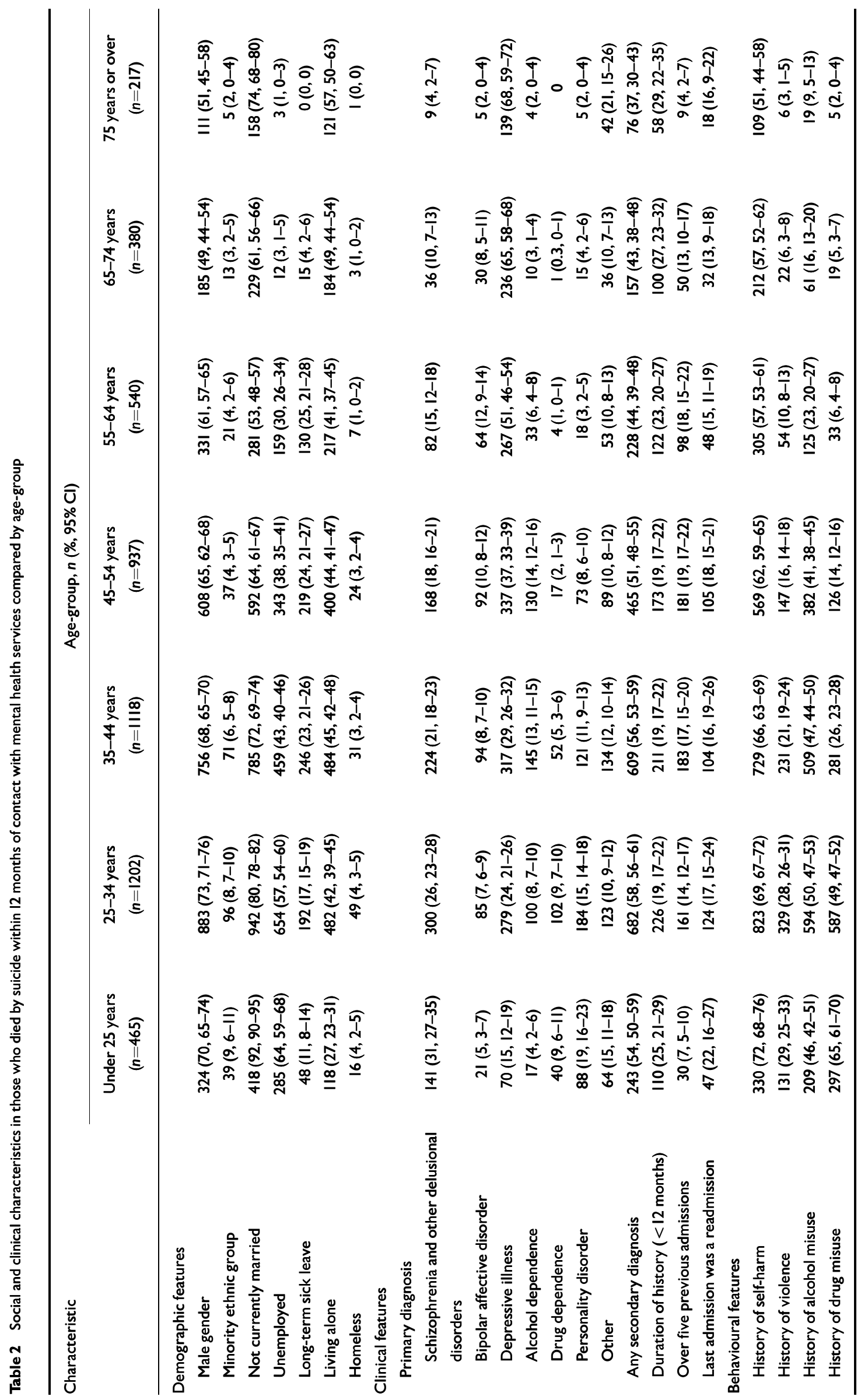


Table 3 Clinical care of those who died by suicide within 12 months of contact with mental health services compared by age-group

\begin{tabular}{|c|c|c|c|c|c|c|c|}
\hline \multirow[t]{2}{*}{ Clinical care } & \multicolumn{7}{|c|}{ Age group, $n(\%, 95 \% \mathrm{Cl})$} \\
\hline & $\begin{array}{l}\text { Under } 25 \text { years } \\
\quad(n=465)\end{array}$ & $\begin{array}{c}25-34 \text { years } \\
(n=1202)\end{array}$ & $\begin{array}{c}35-44 \text { years } \\
(n=1118)\end{array}$ & $\begin{array}{c}45-54 \text { years } \\
(n=937)\end{array}$ & $\begin{array}{c}55-64 \text { years } \\
(n=540)\end{array}$ & $\begin{array}{c}65-74 \text { years } \\
(n=380)\end{array}$ & $\begin{array}{c}75 \text { years or over } \\
(n=217)\end{array}$ \\
\hline \multicolumn{8}{|c|}{ Clinical care at time of death } \\
\hline In-patients & $89(19,16-23)$ & $209(17,15-20)$ & $164(15,13-17)$ & $125(13,11-16)$ & $94(17, \mid 4-21)$ & $57(15,11-19)$ & $16(7,4-11)$ \\
\hline $\begin{array}{l}\text { Post-discharge (with- } \\
\text { in } 3 \text { months) }\end{array}$ & $89(19,16-23)$ & $283(24,2 \mathrm{I}-26)$ & $263(24,2 I-26)$ & $233(25,22-28)$ & II5 (2I, 18-25) & $77(20,16-24)$ & $42(19,14-24)$ \\
\hline Under CPA & $203(44,40-49)$ & $554(47,44-50)$ & $500(45,42-48)$ & $424(46,42-49)$ & $258(48,44-52)$ & $195(52,47-57)$ & $109(51,44-57)$ \\
\hline Missed appointment & $116(32,27-36)$ & $323(34,31-36)$ & $289(31,28-34)$ & $210(26,23-30)$ & $112(26,23-30)$ & $60(19,14-23)$ & $23(12,7-16)$ \\
\hline $\begin{array}{l}\text { Non-adherence in } \\
\text { previous month }\end{array}$ & $101(26,22-30)$ & $264(26,24-29)$ & $211(22,19-25)$ & $151(19,16-22)$ & $83(18,|4-2|)$ & $79(23,19-28)$ & $40(21,15-27)$ \\
\hline \multicolumn{8}{|l|}{ Last contact with services } \\
\hline $\begin{array}{l}\text { Last contact within } \\
7 \text { days of death }\end{array}$ & $224(49,45-54)$ & $564(48,45-5 I)$ & $514(46,44-49)$ & $4 I I(44,4 I-48)$ & $275(52,48-56)$ & $205(55,50-60)$ & II $5(54,47-6 I)$ \\
\hline $\begin{array}{l}\text { Suicidal ideas at last } \\
\text { contact }\end{array}$ & $56(13,10-16)$ & $145(13,11-15)$ & $148(14,12-16)$ & $107(12,10-14)$ & $81(16,13-19)$ & $33(9,6-12)$ & $13(6,3-10)$ \\
\hline $\begin{array}{l}\text { Suicide viewed as } \\
\text { preventable }\end{array}$ & $86(22,18-26)$ & $196(19, \mid 7-21)$ & $207(21,19-24)$ & $178(22,19-25)$ & $107(22,18-26)$ & $57(16,12-20)$ & $45(23,17-29)$ \\
\hline
\end{tabular}

CPA, care programme approach.

Table 4 Cause of death in those who died by suicide within 12 months of contact with mental health services compared by diagnostic group

\begin{tabular}{|c|c|c|c|c|c|c|c|}
\hline \multirow[t]{2}{*}{ Cause of death } & \multicolumn{7}{|c|}{ Diagnostic group, $n(\%, 95 \% \mathrm{Cl})$} \\
\hline & $\begin{array}{c}\text { Schizophrenia } \\
(n=960)\end{array}$ & $\begin{array}{l}\text { Depressive disorder } \\
\qquad(n=1645)\end{array}$ & $\begin{array}{c}\text { Bipolar disorder } \\
(n=391)\end{array}$ & $\begin{array}{c}\text { Alcohol dependence } \\
\qquad(n=439)\end{array}$ & $\begin{array}{l}\text { Drug dependence } \\
\qquad(n=216)\end{array}$ & $\begin{array}{l}\text { Personality disorder } \\
\quad(n=505)\end{array}$ & $\begin{array}{c}\text { Whole sample } \\
(n=4859)\end{array}$ \\
\hline Hanging & $280(30,27-33)$ & $553(34,32-36)$ & $127(33,29-38)$ & $114(28,23-32)$ & $65(31,24-37)$ & $179(36,32-40)$ & $1585(33,32-35)$ \\
\hline Self-poisoning & $194(21,18-23)$ & $543(34,31-36)$ & $107(28,24-33)$ & $192(47,42-52)$ & $101(48,41-54)$ & $181(37,32-41)$ & $1510(32,31-33)$ \\
\hline $\begin{array}{l}\text { Carbon monoxide } \\
\text { poisoning }\end{array}$ & $24(3,2-4)$ & $126(8,6-9)$ & $17(4,2-7)$ & $23(6,3-8)$ & $21(10,6-14)$ & $45(9,7-12)$ & $341(7,6-8)$ \\
\hline $\begin{array}{l}\text { Jumping/multiple } \\
\text { injuries }\end{array}$ & $255(27,25-30)$ & $157(10,8-11)$ & $74(19,15-23)$ & $15(4,2-5)$ & $14(7,3-10)$ & $44(9,6-11)$ & $621(13,12-14)$ \\
\hline Drowning & $8 I(9,7-1 I)$ & $119(7,6-9)$ & $27(7,5-10)$ & $31(8,5-10)$ & $4(2,0-4)$ & II $(2, I-4)$ & $298(6,6-7)$ \\
\hline Burning & $27(3,2-4)$ & $20(I, I-2)$ & $7(2,0-3)$ & $6(1,0-3)$ & $3(1,0-3)$ & $10(2,1-3)$ & $8 I(2, I-2)$ \\
\hline Other & $69(7,6-9)$ & $102(6,5-7)$ & $22(6,3-8)$ & $30(7,5-10)$ & $4(2,0-4)$ & $24(5,3-7)$ & $296(6,6-7)$ \\
\hline
\end{tabular}

I. Includes cutting, electrocution, firearms, suffocation and other specified.

those with alcohol or drug dependence most likely to use this method (Table 4). Violent methods of suicide, particularly jumping from a height or in front of a moving vehicle, were proportionately more common in schizophrenia and, to a lesser extent, bipolar disorder.

\section{Social and clinical characteristics}

Characteristics varied according to primary diagnosis (Table 5). People with a primary diagnosis of schizophrenia were more likely to be unmarried and on long-term sick leave than the other diagnostic groups. Previous violence, drug misuse and comorbidity were relatively common. Only $8 \%$ were in their first year of illness.

In contrast, those with a primary diagnosis of depressive disorder who had died by suicide were least likely to be living alone or unemployed. A third of deaths took place in the first year of illness and few patients had multiple previous admissions.

Individuals with a primary diagnosis of alcohol or drug dependence were predominantly male, unmarried and unemployed, and were more likely to be homeless than the other diagnostic groups. Those with drug dependence had high rates of previous violence and comorbidity.

People with a primary diagnosis of personality disorder had the highest rates of self-harm, violence and drug misuse. Rates of unemployment were high among this group and over half were living alone. The majority of patients with personality disorder had a secondary diagnosis, most 


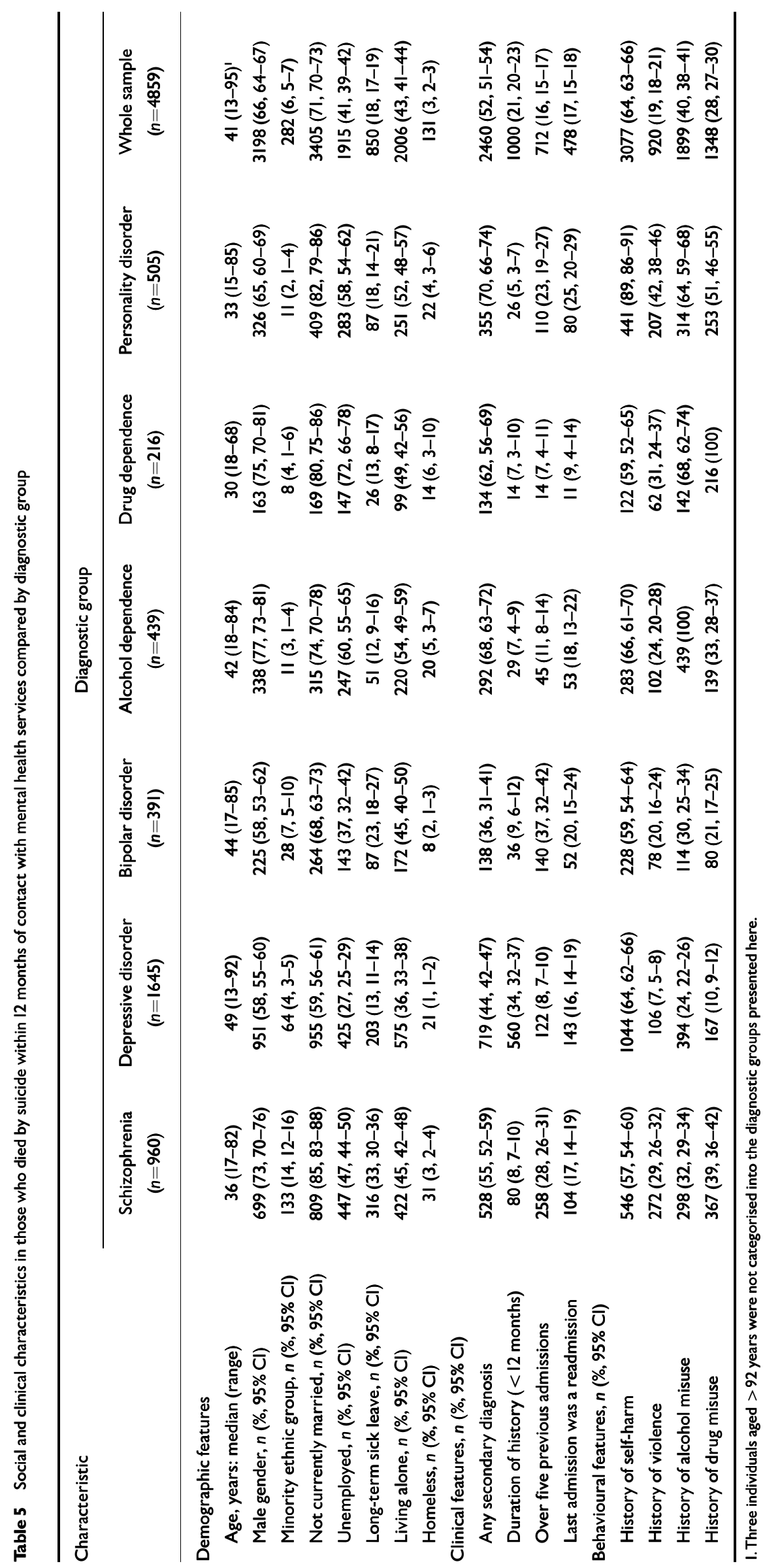


Table 6 Clinical care in those who died by suicide within 12 months of contact with mental health services compared by diagnostic group

\begin{tabular}{|c|c|c|c|c|c|c|c|}
\hline \multirow[t]{2}{*}{ Clinical care } & \multicolumn{7}{|c|}{ Diagnostic group, $n(\%, 95 \% \mathrm{Cl})$} \\
\hline & $\begin{array}{l}\text { Schizophrenia } \\
\qquad(n=960)\end{array}$ & $\begin{array}{l}\text { Depressive disorder } \\
\qquad(n=1645)\end{array}$ & $\begin{array}{l}\text { Bipolar disorder } \\
\qquad(n=391)\end{array}$ & $\begin{array}{l}\text { Alcohol dependence } \\
\qquad(n=439)\end{array}$ & $\begin{array}{l}\text { Drug dependence } \\
\qquad(n=216)\end{array}$ & $\begin{array}{l}\text { Personality disorder } \\
\qquad(n=505)\end{array}$ & $\begin{array}{l}\text { Whole sample } \\
\qquad(n=4859)\end{array}$ \\
\hline \multicolumn{8}{|c|}{ Clinical care at time of death } \\
\hline In-patients & $259(27,24-30)$ & $247(15,13-17)$ & $94(24,20-28)$ & $12(3,1-4)$ & $10(5,2-7)$ & $67(13,10-16)$ & $754(16,14-17)$ \\
\hline $\begin{array}{l}\text { Post-discharge } \\
\text { (within } 3 \text { months) }\end{array}$ & $188(20,17-22)$ & $366(22,20-24)$ & $89(23,19-27)$ & $128(29,25-33)$ & $4 I(19,14-24)$ & $137(27,23-31)$ & $1100(23,22-24)$ \\
\hline Under CPA & $723(76,73-79)$ & $712(44,41-46)$ & $261(67,63-72)$ & $85(20,16-23)$ & $46(22,16-27)$ & $220(44,40-48) \quad 2$ & $2243(47,45-48)$ \\
\hline $\begin{array}{l}\text { Missed } \\
\text { appointment }\end{array}$ & $187(27,24-30)$ & $337(25,22-27)$ & $77(26,2 \mathrm{I}-3 \mathrm{I})$ & $145(36,3|-4|)$ & $78(39,32-45)$ & I3I (3I, 27-35) & II $33(28,27-30)$ \\
\hline $\begin{array}{l}\text { Non-adherence } \\
\text { in previous month }\end{array}$ & $270(30,27-33)$ & $283(20,18-22)$ & $88(25,20-29)$ & $67(20,15-24)$ & $47(27,21-34)$ & $92(22,18-26)$ & $929(22,21-24)$ \\
\hline \multicolumn{8}{|c|}{ Last contact with services } \\
\hline $\begin{array}{l}\text { Last contact within } \\
7 \text { days of death }\end{array}$ & $607(64,61-67)$ & $829(51,49-53)$ & $235(60,56-65)$ & $99(23,19-27)$ & $56(27,2 I-33)$ & $219(45,40-49) \quad 2$ & $2308(48,47-50)$ \\
\hline $\begin{array}{l}\text { Psychiatric } \\
\text { symptoms at last } \\
\text { contact }\end{array}$ & $489(53,49-56)$ & $1098(69,67-71)$ & $248(65,60-70)$ & $279(66,62-71)$ & $137(67,61-74)$ & $337(70,66-74) \quad 2$ & $2990(64,63-65)$ \\
\hline $\begin{array}{l}\text { Suicide viewed as } \\
\text { preventable }\end{array}$ & $189(22,19-24)$ & $358(25,23-27)$ & $93(26,21-31)$ & $57(16,12-20)$ & $26(15,10-21)$ & $52(11,8-14)$ & $876(21,19-22)$ \\
\hline
\end{tabular}

CPA, care programme approach.

often substance misuse or depressive disorder.

\section{Clinical care}

Over a quarter $(27 \%)$ of those with schizophrenia were being treated as in-patients at the time of death (Table 6). Rates of reported non-adherence to treatment were higher than for other diagnostic groups. They were more likely to be detained under the Mental Health Act 1983 than the sample as a whole (47 v. $18 \%, \chi^{2}=72.5$, $P<0.001)$. Those with schizophrenia and comorbid drug dependence were more likely to be out of contact with services compared with those with schizophrenia alone $\left(23 v .11 \%, \chi^{2}=11.0, P=0.001\right)$ and were more likely to be non-adherent to treatment ( $40 v .28 \%, \chi^{2}=7.0, P=0.008$ ).

Individuals with depressive disorder had reported more symptoms at last contact with services compared with the remainder of the suicide sample; symptoms included hopelessness $\left(21 v .14 \%, \chi^{2}=40.1\right.$, $P<0.001)$, suicidal ideas (15 v. $11 \%$, $\left.\chi^{2}=13.1, \mathrm{P}<0.001\right)$ and emotional distress (39 v. 33\%, $\chi^{2}=13.6, P<0.001$ ). Mental health teams were more likely to view suicide in those with depressive disorder and bipolar disorder as preventable $(25 v$.
$17 \%$ of those with other diagnoses, $\chi^{2}=37.2, P<0.001$ ).

Those with alcohol or drug dependence were more likely to have missed their final appointment and were more likely to have discharged themselves or been discharged following a breach of ward rules $(21 \%$ of those with alcohol dependence and 33\% of those with drug dependence compared with $11 \%$ in the remainder of the sample, $\left.\chi^{2}=64.8, \quad P<0.001\right)$. No follow-up appointment was arranged after discharge for $18 \%$ of patients with alcohol dependence and $25 \%$ of those with drug dependence compared with $7 \%$ of the remainder of the sample $\left(\chi^{2}=83.7\right.$, $P<0.001$ ).

Death by suicide within 3 months of discharge from hospital was common among those with personality disorder and rates of loss of contact with services were high. In nearly half $(47 \%)$ of these post-discharge deaths, the last discharge had been unplanned (usually selfdischarge). Individuals with personality disorder were more likely to have revealed suicidal ideas at last contact with mental health services than the remainder of the sample $\left(17 v .12 \%, \chi^{2}=8.7, P<0.01\right)$. Only one in ten deaths in this group was viewed as preventable by mental health teams.

\section{DISCUSSION}

Our findings suggest that the characteristics of people who die by suicide within 12 months of contact with psychiatric services vary according to age and diagnosis. This is likely to have important implications for prevention strategies.

The youngest and oldest age-groups were least likely to be in contact with mental health services, suggesting less potential for these services to prevent suicide in these groups unless measures are taken to engage them further. Younger people more often died by hanging or jumping from a height; older people more often died by self-poisoning (65-74 years) or drowning (65 and over). Compared with older groups, suicide by younger patients was associated with high rates of unemployment, schizophrenia, self-harm and substance misuse. Relationship and legal problems were also more prevalent in younger age-groups. This is consistent with previous studies which found that these life events were relatively common prior to suicide in young people (Houston et al, 2001; Cooper et al, 2002).

In contrast, those over 65 had higher rates of depressive disorder, hopelessness, physical ill health and recent bereavement. 
Our data are consistent with those of other studies which report a preponderance of elderly cases living alone (Cattell, 1988; Harwood et al, 2000). Previous work has identified loneliness and low levels of social interaction as factors that may be important predictors of suicide in older adults (Rubenowitz et al, 2001; Chiu et al, 2004).

In accordance with previous studies, death by suicide in those with schizophrenia was more likely to be by violent means (Rossau \& Mortensen, 1997; De Hert et al, 2001), particularly by jumping from a height (Kreyenbuhl et al, 2002). They were more likely to be in-patients at the time of death and their histories were characterised by complex social and clinical morbidity. Those with depressive disorder were less likely to show typical social and clinical risk factors but a greater proportion died within a year of illness onset.

Cases of suicide with drug dependence, alcohol dependence or personality disorder showed marked recent disengagement from services (e.g. missed appointments and selfdischarge). Services were less likely to arrange follow-up appointments or attempt re-engagement with these patients. Services more often viewed suicide as preventable in schizophrenia, depression and bipolar disorder.

\section{Methodological issues}

Diagnoses in this study were based on the judgement of the clinician most closely involved in the care of the patient rather than standardised interviews. However, a large number of suicide studies have relied on similar methods. In addition the accuracy of Confidential Inquiry questionnaire data has been shown to be good (Appleby et al, 1999). It is also possible that ascertainment biases might have been operating; for example, the likelihood of a suicide verdict being recorded may be influenced by the age or diagnosis of the deceased.

\section{Clinical implications}

The antecedents and clinical characteristics of individuals who die by suicide within 12 months of contact with psychiatric services vary according to age and diagnosis. This was a descriptive study and it was not our intention to carry out a multivariate analysis in order to further explore these differences. Our study does not provide evidence for the effectiveness of preventative measures but it does suggest areas

\section{CLINICAL IMPLICATIONS}

- The antecedents and clinical characteristics of individuals who die by suicide within 12 months of contact with psychiatric services vary according to age and diagnosis.

- Suicide prevention in those under 25 may require comprehensive care packages for patients with schizophrenia, comorbid substance misuse and poor engagement with services, whereas improving the recognition and treatment of depression, the care provided at times of bereavement and the mental healthcare of those with physical illness could reduce suicide among older patients.

Suicide prevention in schizophrenia may be best achieved through improvements to ward safety and multi-agency care plans, whereas suicide prevention efforts in depression might focus on careful supervision, particularly in the first year of illness. Protocols for monitoring and follow-up of patients with a primary diagnosis of alcohol or drug dependence or personality disorder could help to reduce suicide in these diagnostic groups.

\section{LIMITATIONS}

- No control data are available; firm aetiological conclusions cannot be drawn.

- Clinical and demographic information was obtained from retrospective examination of case notes and clinical judgements rather than standardised assessments.

Clinicians providing information may have been biased by their awareness of outcome.

ISABELLE M. HUNT, BSc, NAVNEET KAPUR, MBChB, MMedSc, MRCPsych, MD, JO ROBINSON, MSc, JENNY SHAW, MBBS, MRCPsych, PhD, SANDRA FLYNN, BA, HAYLEY BAILEY, BSc, JANET MEEHAN, MBChB, MRCPsych, HARRIET BICKLEY, BA, REBECCA PARSONS, BA, JAMES BURNS, BA, TIM AMOS, MA, MSc, MBBS, MRCPsych, DPMSA, LOUIS APPLEBY, MD, FRCP, FRCPsych, Centre for Suicide Prevention, University of Manchester, Manchester, UK

Correspondence: Professor Louis Appleby, Centre for Suicide Prevention, University of Manchester, Williamson Building, Oxford Road, Manchester MI3 9PL, UK. E-mail: Louis.appleby@manchester.ac.uk

(First received 4 June 2004, final revision 8 February 2005, accepted 16 March 2005)

in which clinical efforts might be concentrated.

Suicide prevention in young patients could focus on measures directed at preventing hanging (e.g. removing potential ligature points on hospital wards) or measures to impede access to suicide 'hot spots' such as railways and high places. An emphasis on the care of people with schizophrenia, comorbid drug misuse and poor engagement with services might also be helpful. Possible measures include increases in dual diagnosis and assertive outreach services (Appleby et al, 2001). Many young patients live with their families prior to suicide and improved communication between services and families may help to detect warning signs. Reducing suicide in those over 65 requires a different emphasis. Our results suggest that improving the recognition and treatment of depression, the care provided at times of bereavement and the mental healthcare of those with physical illness could be helpful. Services also need to be aware of the possibility of suicide pacts in this older age-group, particularly in the presence of physical illness.

Preventing suicide in patients with schizophrenia might be best achieved by close in-patient supervision, reducing access to violent means of suicide, monitoring 
adherence to medication, and implementing care plans covering both health and social needs, including a multi-agency approach to the treatment of patients with a dual diagnosis (i.e. those with comorbid substance misuse). For patients with depressive disorder, services need to be aware of the risk faced by those who have been ill for a short time, leading to careful follow-up in the period after illness onset. In people with primary substance dependence or personality disorder, clear policies on responding to self-discharge and missed follow-up appointments might contribute to reduced risk. Deaths by those with personality disorder were less often regarded as preventable by staff. Of course this may reflect staff attitudes to the treatability of this patient group. Patients with personality disorder present a particular challenge to conventional services but more specialist service developments may be helpful (National Institute for Mental Health in England, 2003).

\section{ACKNOWLEDGEMENTS}

The study was carried out as part of the National Confidential Inquiry into Suicide and Homicide by People with Mental IIIness. The Inquiry was funded by the National Institute for Clinical Excellence and is currently funded by the National Patient Safety Agency. We acknowledge the help of district directors of public health, health authority and trust contacts, the Office for National Statistics and consultant psychiatrists and other clinicians in completing the questionnaires.

\section{REFERENCES}

Appleby, L., Shaw, J., Amos, T., et al (1999) Safer Services: Report of the National Confidential Inquiry into Suicide and Homicide by People with Mental Illness. London: Department of Health.

Appleby, L., Shaw, J., Sherratt, J., et al (200I) Safety First: Five-Year Report of the National Confidential Inquiry into Suicide and Homicide by People with Mental Illness. London: Department of Health.

Cattell, H. R. (1988) Elderly suicide in London: an analysis of coroners' inquests. International Journal of Geriatric Psychiatry, 3, 25I-261.

Chiu, H. F., Yip, P. S., Chi, I., et al (2004) Elderly suicide in Hong Kong - a case-controlled psychological autopsy study. Acta Psychiatrica Scandinavica, 109 299-305.

Conwell, Y., Duberstein, P. R., Cox, C., et al (1996) Relationships of age and axis I diagnoses in victims of completed suicide: a psychological autopsy study. American Journal of Psychiatry, 153, 1001-1008

Cooper, J., Appleby, L. \& Amos, T. (2002) Life events preceding suicide by young people. Social Psychiatry and Psychiatric Epidemiology, 37, 27I-275.

De Hert, M., McKenzie, K. \& Peuskens, J. (200I) Risk factors for suicide in young people suffering from schizophrenia: a long-term follow-up study. Schizophrenia Research, 47, 127-134.

Department of Health (2002) National Suicide Prevention Strategy for England. London: Stationery Office.

Harris, E. C. \& Barrowclough, B. (1997) Suicide as an outcome for mental disorders. A meta-analysis. British Journal of Psychiatry, 170, 205-228.

Harwood, D. M. J., Hawton, K., Hope, T., et al (2000) Suicide in older people: mode of death, demographic factors, and medical contact before death. International Journal of Geriatric Psychiatry, I5, 736-743.

Hiroeh, U., Appleby, L., Mortensen, P. B., et al (200I) Death by homicide, suicide, and other unnatural causes in people with mental illness: a population-based study. Lancet, 358, 2110-2112.

Houston, K., Hawton, K. \& Shepperd, R. (200I) Suicide in people aged 15-24: a psychological autopsy study. Journal of Affective Disorders, 63, 159-170.

Høyer, E. H., Olesen, A.V. \& Mortensen, P. B. (2004) Suicide risk in patients hospitalised because of an affective disorder: a follow-up study, 1973-1993. Journal of Affective Disorders, 78, 209-217.

Isometsa, E. T., Henriksson, M. M., Hillevi, M. O., et al (1994) Suicide in major depression. American Journal of Psychiatry, I55, 530-536.

Isometsa, E. T., Henriksson, M. M., Heikkinen, M. E., et al (1996) Suicide among subjects with personality disorders. American Journal of Psychiatry, 153, 667-673.

Kreyenbuhl, J. A., Kelly, D. L. \& Conley, R. R. (2002)

Circumstances of suicide among individuals with schizophrenia. Schizophrenia Research, 58, 253-26I.

Meehan, J., Kapur, N., Hunt, I. M., et al (2006) Suicide in mental health in-patients and within 3 months of discharge. National clinical survey. British Journal of Psychiatry, 188, 129-134.

National Institute for Mental Health in England (2003) Personality Disorder No Longer a Diagnosis of Exclusion: Policy Implementation Guidance for the Development of Services for People with Personality Disorder. London: Department of Health.

Rossau, C. D. \& Mortensen, P. B. (1997) Risk factors for suicide in patients with schizophrenia: nested casecontrol study. British Journal of Psychiatry, I7I, 355-359.

Rubenowitz, E., Waern, M., Wilelmson, K., et al (200I) Life events and psycho-social factors in elderly suicides - case-control study. Psychological Medicine, 31, 1193-1202.

Timonen, M., Viilo, K., Vaisanen, E., et al (2002) Burden of illness and suicide in elderly people. BMJ, $\mathbf{3 2 5}$, 441.

World Health Organization (1992) The ICD-10 Classification of Mental and Behavioural Disorders. Geneva: WHO. 